\section{An ecosystem perspective in the socio-cultural evaluation of dengue in two Colombian towns}

\author{
Uma abordagem ecossistêmica à avaliação \\ sócio-cultural da dengue em duas cidades da \\ Colômbia
}

\footnotetext{
${ }_{1}$ Facultad de Ciencias Sociales, Universidad de los Andes, Bogotá, Colombia. 2 Centro de Estudios e Investigación en Salud, Fundación Santa Fe de Bogotá, Bogotá, Colombia.

Correspondence R. Suárez

Departamento de Antropología, Facultad de Ciencias Sociales, Universidad de los Andes. Carrera 1 E \# 18 a 10 Edificio Franco 5o piso, Bogotá, Colombia.

rsuarez@uniandes.edu.co anmedica@uniandes.edu.co
}

\begin{abstract}
Despite extensive public health efforts, dengue is still a major health concern in Colombia. The objective of this study was to provide an ecosystem and cross-disciplinary perspective on the dengue situation in two Colombian towns. The article focuses on presenting the anthropological methodology and research findings. An interdisciplinary team gathered quantitative (crosssectional), meteorological, entomological, and qualitative data (based on medical anthropology) through fieldwork and archival research. According to the qualitative data, dengue can be described as a point of convergence between public health policies, the affected population, the environment, and the social dynamics generated through this interaction. Dengue is illustrative as a disease, in that it has a negative impact on public health, but individuals in Colombia have learned to live and cope with it. Dengue prevalence and its on-going historical presence have made it part of everyday community life, viewed as a minor health issue.
\end{abstract}

Dengue; Ecosystem; Communicable Diseases
Roberto Suárez ${ }^{1}$

Catalina González 1

Gabriel Carrasquilla 2

Juliana Quintero ${ }^{2}$

\section{Introduction}

Dengue in Colombia: a challenge for public health

In the context of public health, traditional approaches have relied upon one-dimensional views which are always too narrow to explain why dengue is, still, a major social, health, economic and ecologic issue $1,2,3,4,5$. These studies have followed a clear methodological tendency based on a behavioral approach to understanding human behavior in order to shed some light into vector transmitted disease. The use of this type of research seeks to give rise to behavior change in populations in order to promote lifestyles that improve human health. To achieve this goal, the community has been placed as a key element and as a full time partner in the construction of disease prevention and vector control programs 6 . Nevertheless, reality has shown that in some cases it has been a positive experience, while in many others it has been an incomplete process. In examples of the latter, the community has become a policy token to legitimate and validate health interventions 7,8. Following this perspective, poverty and ignorance are seen as the fundamental causes of disease, thus oversimplifying the complexity of the problem while narrowing the understanding of dengue to the links between social conditions and vulnerable communities exclusively 9,10. Dengue, despite 
all efforts is still a public health issue and represents an important challenge for public health programs 5,11,12. Overall, the influence of social and cultural aspects in dengue transmission has been overlooked. However, social actors involved in public health and different researchers have pointed out the necessity to take these two variables into consideration in order to develop competent control and prevention programs $11,13,14,15,16,17,18,19,20$. The underlying idea is to understand dengue as a bio-anthroposocial event that takes into account the interaction between biological, epidemiological, social and cultural data in order to clarify their linkages 21,22 .

We carried out a transdisciplinary study to assess linkages between eco-bio-social factors and the current dengue situation in two cities of the Magdalena river basin in Colombia. We proposed a descriptive study that collected historical information of the past five years regarding dengue epidemiological data from the two cities as well as entomological information already available for the study area. Ecological variables such as climate, demographic information, health system and health sector reform, including the decentralization process, and social, economic and political information were also collected. In addition, in order to assess geographic mobility, health itineraries, medical culture and also current entomological data and epidemiological information a transdiciplinary study took place divided into a cross sectional and medical anthropology research. We hypothesize that many of these factors (as yet neglected scientifically) are important determinants of the occurrence of Aedes aegypti in urban areas in Colombia and have a direct impact, however complex, on dengue control measures and prevention.

This article is focused on the presentation of the anthropological methods and findings of the research project. Therefore, the results section presents the local perceptions and values given to health and disease and particularly to the phenomena of dengue in the region. Local knowledge and cultural practices associated with dengue gives us a complex view that reveals the social and cultural determinants of the reality of dengue in this region of Colombia.

\section{Medical anthropology research methodology}

The research work of the medical anthropology group was based on qualitative ethnographic methodology. Fieldwork was carried out between November 2004 and January 2005.
Three specific data gathering methods were implemented: in-depth interviews $(\mathrm{n}=72)$ with health promoters, key stakeholders, and community members selected through critical case sampling 23,24,25 and snowball referral; focus group discussions $(n=6)$ with health promoters and community members; and direct social observation within the cities.

In order to determine how to initiate the fieldwork, it was decided to find critical cases that could offer us an initial sample and could allow us to set in motion the snowball referral. Critical case sampling permitted us to identify information rich cases in Girardot ( $n=6)$ and Melgar $(n=$ 6) that provided us with critical information to organize the sample by snowball referral within the selected epidemiological sample. A critical case was chosen according to the following inclusion criteria: (1) to have lived in the study area for at least the last two years; (2) to be or have been in contact with dengue infection; and (3) to be a consenting adult. Each interview was analyzed by the number and quality of information provided for each topic by the interviewee in order to be considered a critical case.

The main instruments for data collection were three interview questionnaires adapted to the population (health promoters, stakeholders, community) based on 15 topics which constituted our guidelines rooted in our conceptual framework (Figure 1): mobility patterns, productivity patterns, sanitary practices, education level, household characteristics, use of pesticides, household organization, neighborhood characteristics, medical culture/health-disease perceptions, medical pluralism, therapeutic itineraries 6,26 , risk perception/vulnerability self perception 27,28 , intra-household resource distribution, everyday cognition 29 and gender. Within each topic a range of variables were considered according to the emphasis of the interview and additional questions were conducted to follow up the dialogue. Focus groups discussions with health promoters and community members allowed us to complement information regarding local perspectives on the impact of public health intervention strategies that have been pursued in the region, and to compare the information obtained in groups with that obtained through personalized household visits and interviews. During fieldwork, individual in depth interviews with key stakeholders were carried out to favor open responses about qualitative aspects of dengue and avoid responses that may be influenced by peer pressure.

Throughout the data collection phase, during household and health center visits, direct social observation was carried out as an on- 


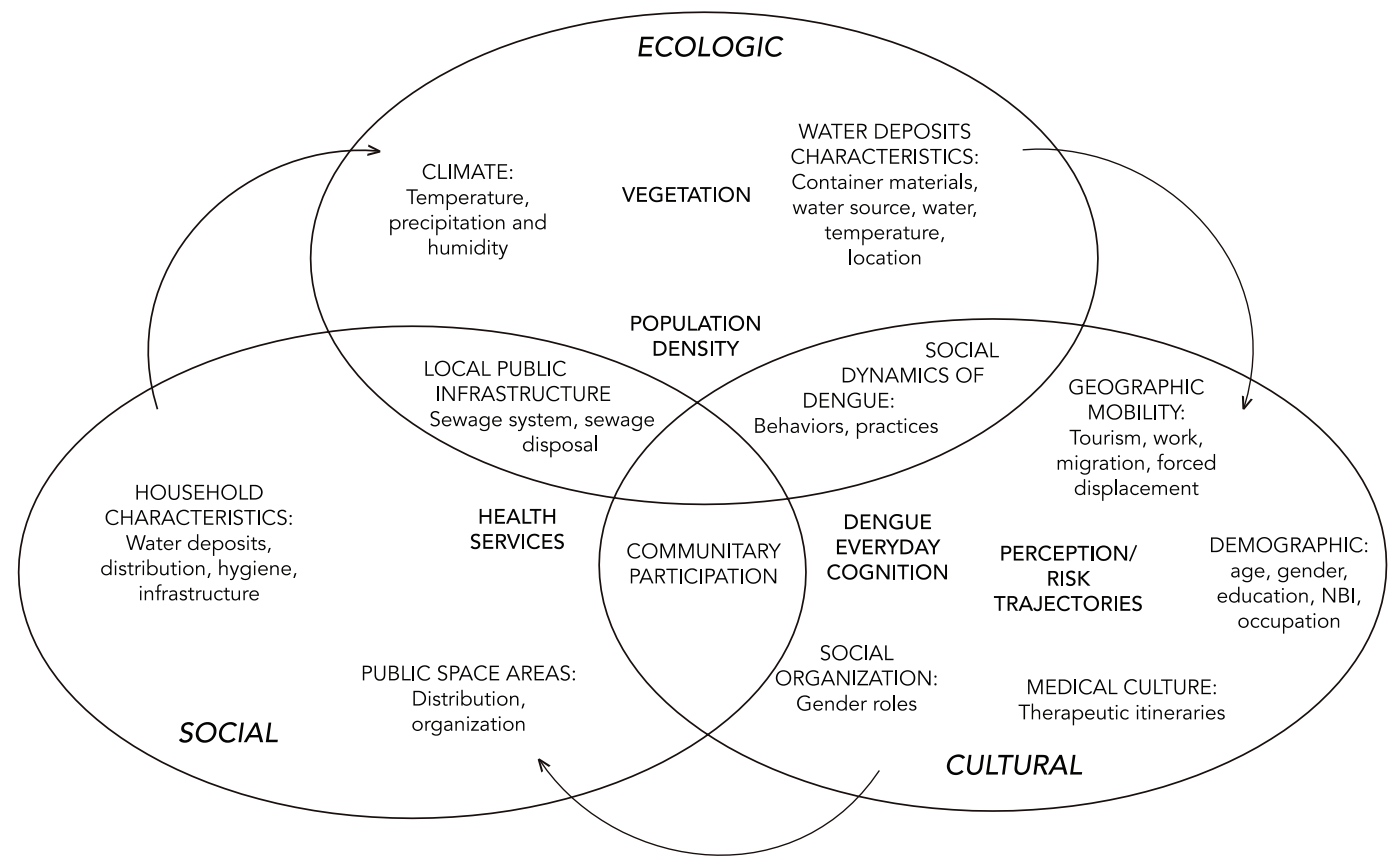

Source: Lebel 30

going research process, as well as observation of village life, hygiene conditions, and places that could represent a risk factor or potential larvae breeding sites.

\section{Qualitative data analysis}

The data obtained from all qualitative techniques was manually sorted, entered, and systematized into the computer. The software ATLAS.ti version 5 (Muhr T. Scientific software development Gm$\mathrm{bH}$, Berlin, Germany) was used in order to categorize data, following content analysis strategies $31,32,33$. For this purpose, open codes (a word or phrase than can relate data within a similar meaning or context) were created. As a first step, codes were produced according to the conceptual framework. However, as the interviews were analyzed, new codes were added. A total of four code families were created, collecting semantic relationships around culture, everyday cognition, health promotion and social dynamics. With code families assigned, the next step was to relate them to each other. Through code que- ries, binary code families were crossed with the purpose of finding semantic relations between them. The results of binary queries were unified as a supercode, a strategy that ATLAS.ti uses to gather an outcome. With all supercodes related, a final supercode was created, containing previous outcomes of semantic relations. The name of the ultimate supercode is "cultural artifact", proposed after triangulation discussions aimed at explaining the dengue situation in Melgar and Girardot. A cultural artifact is defined for this research as a social construction elaborated through a dynamic process where several actors and institutions participate and converge and, that is embodied in specific historical, economic and social reification processes 34 . Therefore, a cultural artifact is not understood as a material object but as constructed representations to which the community attaches social meanings.

\section{Profile of the region}

The regional characterization of the two different municipalities under study is based, pri- 
marily, on the homogeneity of their natural and geographic profile. However, beyond this identification, it is necessary to acknowledge that Girardot and Melgar are located within a region that has been construed through historical, social and cultural processes, which over time have brought down political and administrative barriers and boundaries 35. Thus, Girardot and Melgar have been classified as tourist territories in lower lands, what has been historically known in Colombia as "tierra caliente" meaning warm lands 36 .

Currently, in contrast to this temporary tourist population there is a displaced population that has been migrating to the area due to the country's political and economic difficulties. These new populations have established themselves in vulnerable and deprived social conditions alongside rivers or within the poorest neighborhoods.

Linked to this situation, it is worth mentioning that within the region of Melgar and Girardot different types of enclaves - military, such as Tolemaida and tourist, such as El Peñón - have developed. Within these enclaves specific social organizations have formed that have clearly drifted away from local policies implemented by the municipalities.

\section{Results}

"You grow strong and healthy in this region": health culture in the low lands of Girardo and Melgar

Immersed within the contemporary cultural diversity of the Colombian population, the importance within the health field of social and cultural differences becomes manifest. In this process, health and disease can be understood as culturally and socially constructed categories resulting from the permanent relationship between a particular human context and its environment.

"People from here are very healthy and strong, you grow eating mount meat (...) and that gives you a strong constitution" (Community respondent, 2005).

Health cultures here refer to all phenomena associated with health and the disruptions of health in a specific place or social group. It delimitates traditions and notions about what is considered a disease or not and embraces cognitive dimensions and social contexts. Taking into account these ideas, the intention of this first section of results is to present a detailed overview of the complexity of the health culture of the region. For this reason, the categories of health and disease are described and analyzed from a social and cultural perspective in order to comprehend how social meanings and dynamics are articulated to provide sense and praxis to both categories. Furthermore, dengue is a category that surpasses a classical biological approach allowing the possibility to view it as a social fact in which different factors intervene including social forces, knowledge, and social practices such as therapeutic itineraries.

"People from the big cities like Bogotá tend to get sick... here in the rural areas we are healthier" (Community respondent, 2005).

Social perceptions of health and disease in the everyday lives of people from the region of Girardot and Melgar, are rooted in cultural images of strength and weakness. The notion of strength is understood as a quality to those that are native to the region and permits them to cope ably with the disease, whilst visitors are regarded as weak or not physically and culturally fit to deal with the region's maladies, such as dengue.

Therefore, being healthy and being sick correspond to the individual and social experiences of health and its disruptions in a complex way in which biological, cultural and social factors give meaning to health related categories. In this particular context the notion of strength is linked to those born in the lowlands such as Girardot and Melgar, places socially perceived as harsh environments for human life due to its tropical climate and its rural context. Therefore, natives of the region have the "natural" ability to cope with the harshness of the place. On the contrary, if you are a foreigner such as a tourist, and particularly from the highland areas such as Bogotá, you are considered to have a propensity to illness. This specific population is regarded as a group that is at greater risk of falling ill in the region, due to its members' constitutions, considered inappropriate for dealing with lowland life. The self-reported health of lowland natives is based on their competence to cope with unfriendly environmental conditions. Animals, bugs and heat do not represent a risk; they are elements that must be lived with. Furthermore, the subjective experience about health is the foundation that defines what is disease, how it should be prevented and which kind of therapeutic practices should be implemented.

"We are very healthy, we rarely get sick... maybe the kids get a mild flu once in a while and they are given medicine at the health center" (Community respondent, 2005). 
That thing called dengue: the folk flu syndrome

When seeking to understand dengue as a complex reality, there is a need to ask one fundamental question: what is dengue for the population? First of all, in order to respond to this question it is necessary to characterize it as a cultural artifact in the everyday life of this population. In other words, dengue may be understood in the first place as an event that can be reified, an event that turns into an object attached with meaning through a social process where several actors and institutions participate and converge, and that is embodied in specific historical, economic and political processes in the Girardot and Melgar region. In such terms, then, what is dengue? Dengue can be described as a converging point between public health policies, the affected population, the environment, and the social dynamics generated through their interaction.

Secondly, throughout the fieldwork it was clear that dengue contains features that make it a socially constructed category; dengue was classified as synonymous with a common cold or flu. This perception attributes a social value to dengue. The narrative of "just a cold" diminishes the sense of being at risk, while enhances individual self perceptions for coping with the symptoms, thereby outlining a knowledge of the disease and a set of activities. Fever as a common symptom of flu has no disability value from the community's perspective

"Are you asking me if there have been any dengue cases? You mean flu? Or hemorrhagic dengue? 'cause here dengue is simply a common flu or cold. We call it the same; a flu is like having dengue. The one we fear is hemorrhagic dengue 'cause that one is dangerous and it can kill you (...) yet dengue is the common fever, with bone pain which is common, just common dengue (...) regular flu" (Community respondent, 2005).

The word dengue covers a wide spectrum of definitions that vary from a mild flu to a bonebreaking fever, but the whole continuum shares a basic defining characteristic: dengue can be controlled with cold medicine available over the counter, or, by taking care of the ill person at home, without the need for a medical consultation. As long as the most recognized symptoms: fever, and headache correspond to the social knowledge of the disease these signs are considered a minor affection that do not fall into the significant category of illness. However, if the symptoms worsen, and particularly if hemorrhage appears, the spectrum of dengue enlarges into a new category were hemorrhagic dengue is seriously considered, and a whole new meaning is given to the condition. The presence of hemorrhage implies a very dysfunctional state of the body that attributes danger to the condition of the affected person. While having a common flu-dengue or diarrhea is not associated to being sick, the new symptomatology that involves bleeding, is associated with trauma, and is given the category of an illness.

"When people have dengue the symptoms are fever, vomit, diarrhea, and blood platelets drop, but when they start bleeding and the diarrhea worsens that's when they go to the hospital, there they will tell you if you have dengue or hemorrhagic dengue" (Community respondent, 2005).

The points of view expressed in the interviews reveal the presence of complex social knowledge on the subject. Even though the population frequently refers to the symptoms as "that thing called dengue", its meaning is culturally negotiated through diverse sources of information, and in the course of experience it is modulated within health cultures in the communities of both municipalities. Dengue is part of their everyday life and in that sense it is not perceived as a menace, but as one of the many traits of their environment. The Aedes aegypti vector is just one more insect among many others. Mosquitoes belong to the tropical ecosystem of the region; their presence in the environment is so ordinary that individuals do not perceive mosquitoes as a menace. Mosquitoes are just one more element involved in dealing with everyday life.

Dengue is recognized, primarily, as a folk flu by the population and, consequently its treatment corresponds to those associated to a virosis. Nevertheless, it is important to note that it also covers a wide spectrum of definitions that run from a mild flu to a very dysfunctional state of the body, specifically when hemorrhage appears and therefore hemorrhagic dengue is recognized. Due to this broad cognition of dengue, therapeutic responses have an extensive pool of options. Taking into consideration people's objectives in their everyday lives, when a health problem disrupts usual routines, individuals construct therapeutic itineraries that could offer a solution to their state. A therapeutic itinerary is an operative category that serves to describe therapeutic trajectories among the individuals seeking to find a competent solution to their health problems. They are built based on self reported health, a subjective assessment of the disease, their therapeutic savoir-faire, perceptions of risk, and available resources in the biopsycosocial environment.

Through qualitative research several tendencies were identified. Choices such as the 
pharmacy, over the counter medication, self care, and traditional medicine are used by those that do not opt for medical consultation as their first option. This situation reveals the importance of comprehending the complexity of the social dynamics regarding dengue as a social reality and furthermore as a social category where knowledge and everyday performance remains a paradoxical relationship. What people know and say about dengue does not necessarily correspond to what they do, think, feel, and experience about the disease in everyday life.

"People that manifest dengue symptomatology assume the condition is a virosis, like flu. When they finally consult the doctor their health state is very complicated ... they go when their daily activities are interrupted because of their illness. Most of the times, they come because they can't handle the situation anymore" (Community respondent, 2005).

To face this fact is a challenge for health workers because it questions efforts to control and prevent the disease; first of all, it becomes evident that people know about dengue; secondly it shows that everyday cognition of dengue and medical knowledge are not in opposition; thirdly, that efforts to influence a behavioral change in order to have healthy lifestyles are based on a cognitive dissonance with local realities; and, last but not least, bridging public health ideals with the life of people demands that the rigid guidelines included in some public health plans be overridden.

Who really cares about dengue? Risk perception and social dynamics

After completion of the fieldwork and literature review, one fundamental question remains. Does dengue, as a disease, represent a problem? As a starting point, the qualitative findings support the statement that, from the population's point of view, dengue is not and has not been a major health issue.

"Well, the truth is that there is a lot of dengue around here, in fact, one of our neighbors is very ill and a relative too, we don't even go there anymore, so that we don't catch it [the disease]..." (Community respondent, 2005).

Thus, the perception of dengue as a problem arises only when it is linked to a neighbor. In other words, the community within the municipalities of Melgar and Girardot do not perceive the disease as a concern. It only becomes problematic when it is associated with a neighbor. In this sense, the neighbor becomes a dangerous 'other' that could have a negative impact in the health on the household.
It is the other that lives close enough to endanger the community. In the case of this study, it refers to those individuals living close rivers and to the confluence of the Magdalena and Bogotá rivers. Results from fieldwork showed that dengue is highly associated with the poor and especially to those living near the confluence of the Magdalena and Bogotá rivers, an area which the research group named the 'evil vortex'. Subsequently, the community's perspective indicates that the reemergence of this disease, and the risk that it may represent, is limited to a section of the community - the poor - and particularly those confined to the convergence of these two rivers. Even people from lower social strata consider that the risk is limited to people living on river banks.

But, what seems more relevant is that people from that zone denied the presence of dengue and recurrently affirmed that they almost never get sick.

"People have lived here for more than six years and no one has fallen sick... that I know of" (Community respondent, 2005).

"No ma'am, here no one gets sick and there are not really many mosquitoes due to the breeze" (Community respondent, 2005).

The community considers the 'evil vortex' to be a tangible place where dengue is a real problem. In their narratives, because of the presence of two rivers, the lack of public services and a general state of poverty, dengue has a perfect breeding site. Entomological technicians, working for the local health secretaries, also share this view.

"That illness [dengue] predominates, more than anywhere, around us, the poor. Because, if suddenly someone enters a house of stratum $5, o b$ viously they're not going to find as many larvae as can be found in a poor house" (Community respondent, 2005).

\section{Water containers and management of breeding sites}

The uses of water and water containers have important implications for vector indexes. How people use those objects allows us to understand another side of prevention practices and to outline the links between breeding sites and how people relate to them in their daily lives.

"Here I have a low water tank, I wash it every two or three days. We don't have fishes" (Community respondent, 2005).

"They [health promoters] have told us to clean the tank at least once a week, but to be honest, we can't clean it weekly. We clean it, honestly, every month or maybe it takes even longer for us to clean it" (Community respondent, 2005). 
As these quotes suggest, two ideas come into sight from cleaning the low tanks. First of all, for the region inhabitants, dengue is a matter of what is clean and what is dirty; larvae can breed as well in dirty places, thus ensuring that all deposits are clean is a key control strategy. Although they know that dengue breeds in stagnant clean water, they still keep clean water stored because these tanks represent a water reserve that historically is needed in the region.

Having clean deposits sometimes implies rejecting biological control measures such as fish. According to an entomological technician, some people dislike fish; because of the excrements, water is no longer clean. However, biological control has a relevant place as a control measure as well as good standing within the community. As could be stated by observations and the interviews, most households indeed have fish.

"To keep the tank filled with fish so there won't be any larva" (Community respondent, 2005).

Considering the narratives regarding cleanliness, chemical control measures are also accepted within the community. Some people put some drops of chlorine to kill larvae; hence they do not use fish or other animals.

"We don't have fish here because chlorine kills them... or when you use boiled water" (Community respondent, 2005).

The acceptance of chemical control is based on the conservation of water properties, such as color and smell. Nevertheless, people comment that temephos is good, but it remains perhaps too much time in the tanks and losses its efficacy.

The information shows that people from lower social strata have considerably more risk of having dengue vector forms, and that people perceive those sectors as the only area where dengue is a real problem, particularly the area denominated the "evil vortex". The common characteristic of these areas is not having a house-built tank, but rather a plastic or metal container filled with water. When asked about their tanks, people from lower strata areas replied in the following fashion.

"We don't have a water tank, instead we use a container and they have dropped a little bag with chemicals" (Community respondent, 2005).

Although it is more frequent to observe plastic containers in lower strata, this situation is more generalized in Melgar due to problems of water availability. Melgar over the years has had an increasing problem with water supply, where it is common for the service to be suspended during weekends. On weekends, most residential zones have less supply because hotel and tourist zones get the benefits.
"I have lived right here for more than ten years without water service, so after calling everyday, and arguing with them they bring us a water-tank car and you have to store as much as you can in containers" (Community respondent, 2005).

While in lower stratum areas plastic water containers are used for laundry and potable water storage, higher stratum areas use washing machines and their own water supply system like the case of the El Peñón enclave. This recreational condominium, although not permanently inhabited, used to have their own water supply, but recently, the service is provided by the municipality. This situation enhances the invisibility of dengue among the higher classes. For example, because of the presence of washing machines, people do not see why they have to take extra control measures with water deposits. Health promotion personnel see this perception as a limitation, and acknowledge that most control measures are based on the tanks and in their absence, it is difficult for them to present the link between any kind of water deposit and breeding site. However, an entomological technician presents a different view of the situation. For him, people do not wash their tanks very often because of water expenses. In order to save it, people tend to store water so they can control how much they use.

"And you tell more people: 'please try to clean your deposit at least once a week and the community response is: are you going to help me pay my water bill?" (Community respondent, 2005).

This result suggests that higher tanks are not cleaned as often as low-domestic tanks, perhaps because they are not used on a daily basis. The only control measure that seems to be effective so far is to cover higher tanks. Other preventive measures studied related to actions taken towar$\mathrm{ds}$ waste disposal. If recycling represents a higher risk of having infested households, why do people do that? Most people interviewed knew that having disposables around the house represents a possible breeding site.

Furthermore, the interventions included in local health promotion plans always alert participants to the possible risks of having those items and people have integrated those recommendations into their everyday awareness. Even without interventions, people would take care of discarded containers following the logic of clean vs. dirty. For the community, it is important not to have any kind of container because those may not be considered tidy. Keeping those containers may represent other values besides cleanliness, such as usefulness. Although the risk of recycling is greater, through observations it can be affirmed that discarded containers are used inside or 
outside for various purposes, such as flowerpots and gardening, animal water bowls, decoration or just for trading them for money. In light of these, discarded containers are not precisely seen as risk spots but, as useful items within households. Recycling is a social dynamic rooted in social customs and logics accepted by the communities. However, this view is not shared nor validated by health promoters; for them, having discarded containers represents a high risk behavior, based on people's ignorance and laziness.

\section{Discussion}

We have sought to articulate different variables that, with all certitude, are interdependent to produce what we refer to in the document as "that thing called dengue". On this point, two elements have become crucial to develop an understanding. The first one is the social perception of the disease and how this perception is shaped by our second element "knowledge". Both elements render explicit all the contradictions involving this disease. When trying to conduct a social appraisal of the population's perception, it is pivotal to emphasize everyday aspects such as the way the community names, frames and gives meaning to the disease $37,38,39$. In this sense, eco-biosocial and cultural dynamics are interwoven to provide and anchor the idea of dengue for the local context in categories that describe the disease as: "folk flu syndrome", "virosis", or "just another cold"; which are all narratives that express the variability of meaning attached to a particular phenomenon 6,28 .

Dengue as a disease can be understood through the category of the other. This disease always has a social attribution to a neighbor, a neighborhood, people from the middle or low social strata, while the poorest attribute it to another region. What is important is to state that the definition of dengue is the result of people's cognition situated in a specific context and time in their life stories; in other words in their social and individual experience. When seeking to comprehend the reality of this disease in everyday life we are continuously confronted with people that posses a knowledge that is the result of the interweaving of different ways to approach a single phenomenon, in this case of dengue. In this sense, there is no such thing as adequate knowledge; what might be perceived as adequate to some may be considered awkward by others. The importance is not if it is adequate or not at the time of planning a program, but if the disease is perceived in its full complexity 28.
The problem of perception and knowledge leads us to another important issue regarding dengue control and prevention. How do individuals face the disease? Therapeutic itineraries, as described by the population, express the issue of what is at stake when you have "that thing called dengue". Also, it expresses the essence of what is to be considered a disease and a risk behavior, and which measures individuals follow in order to cope with their ill health. All the above ideas validate that biomedical resources are not the only ones available; on the contrary they represent one among many available resources that people resort to within their close environments to find answers 27,28 .

Girardot and Melgar are found within a lowland region and have a life story where water has had a particular status. Water management is therefore central to their daily functioning ${ }^{39}$. The water is something important to everyone, but historically the experience of water shortages has been a continuous fact. In order to deal with this reality people have developed social dynamics that have allowed them to store it, keep it, and ensure its cleanliness. The evident result is that the low tank and the proliferation of this object is an essential commodity that everybody must possess within their households. Therefore, an object that gives people the possibility to have a better standard of well-being can not be perceived as a disease niche. Here we face an oxymoron: why lower tanks suggest the existence of a dirty cleanness? So why clean what is already clean? And then a paradoxical situation for public health interventions: the need to keep water clean is incompatible with the association between breeding sites, low tanks and disease 40 .

Public health policies in the region are purposely designed for the control of intra-household low tanks - either biological or social control. Nevertheless, focusing on the cleanliness of low tanks diminishes the idea of risk while it transmits the following message: "if I do not have a low tank I am not at risk, but if I do have a low tank and I follow all the guidelines regarding care of it, I am not at risk, even though there are all kind of disposables that I am not aware of' (Community respondent, 2005). In consequence, the foundations of public health policies that focus on low tanks and disposables collection represents an oversimplified view of the disease. It also fails to allow for competent programs that are culturally and socially sensitive. Finally, the problem related to the axis of water management, water storage, risk perceptions and social conditions is a complex relationship that needs to be translated into concrete actions that find a coherent solution to social groups' reality; for instance, social depriva- 
tion leads to a wider vulnerability, and well to do conditions tend to make possible risk conditions invisible 6,21,41,42.

\section{Conclusions}

To date, dengue is a good example of a disease that, although it has a negative impact on society from an epidemiological point of view, individuals in a country like Colombia have learned to live and cope with it, making dengue part of their everyday life. Dengue is a result of their social and cultural history and an event that is frequently described within their health narratives that is not perceived or associated to a health risk and, consequently is not a major burden as it certainly represents a form of social and economic deprivation. Furthermore, the prevalence of dengue has made it an everyday health experience that is embedded in popular knowledge, thus making the disease a minor issue for the community health status; it is perceived as an incident that could disrupt everyday life without a significant, negative effect and, consequently does not require exceptional consideration or care. But, from a public health perspective, it is without any doubt, necessary to reduce frequencies of the disease, reduce the social determinants that favor its re-

\section{Resumo}

Apesar dos esforços de saúde pública, a dengue continua sendo uma grande preocupação de saúde na Colômbia. O objetivo deste estudo é de fornecer uma perspectiva ecossistêmica e transdisciplinar em relação à situação da dengue em duas cidades colombianas. O foco principal do artigo é a apresentação da metodologia antropológica e dos achados da pesquisa. Uma equipe multidisciplinar coletou dados quantitativos (transversais), meteorológicos, entomológicos e qualitativos data (baseados na antropologia médica), através de trabalho de campo e pesquisa de arquivos. Com base nos dados qualitativos, a dengue pode ser descrita como ponto de convergência entre políticas de saúde pública, a população afetada, o meio ambiente e a dinâmica social gerada por essa interação. A dengue é um bom exemplo de uma doença com impacto negativo sobre a saúde pública, mas com a qual os indivíduos em um país como a Colômbia aprenderam a lidar e conviver. A prevalência da dengue e sua presença histórica persistente tornaram a doença parte da vida cotidiana da comunidade, vista como um problema de saúde menor.

Dengue; Ecossistema; Doenças Transmissíveis production, as well as to fulfill the need to implement programs seeking to influence a behavioral change and a societal change. Yet, in order to bridge both realities maybe our next step is to ask us about the future of dengue control? Dengue has demonstrated the need to find alternative pathways to control the disease. Colombian health plans and public agendas have followed the recipes of international health programs that have quickly turned sour due to the social reality and global development. It is important to build a more refined health agenda to control dengue based on social, cultural, epidemiological, biological, political and economic spheres that take into account individual and societal history.

But how could this become a reality? Possibly, a first step towards this direction is to reconsider the role and place of medicine and public health in society. Using the words of Virchow 43 which expressed the need to establish medicine as anthropology because essentially medicine is a social science, we could start a process in which the health field advances in a social direction to build programs that embrace all aspects of dengue as well as the people that endure the consequences of it. In short, consideration of the eco-biosocial perspective could allow for societal growth but also for the construction of a suitable disease control agenda.

\section{Contributors}

R. Suárez acted as a field work researcher and was responsible for data gathering, data analysis, organizing concepts and writing the article. C. González was also a field work researcher, responsible for data gathering, data analysis, organizing concepts and writing the article. G. Carrasquilla carried out data analysis, organized concepts and helped in writing the article. J. Quintero acted as the quantitative researcher, performed data analysis, organized concepts and contributed to the writing of the article.

\section{Acknowledgments}

We owe a great deal of gratitude to all informants and local authorities from Melgar and Girardot. Also, we are indebted to the University of Los Andes and the Fundación Santafé for their help and support throughout this research. Last but not least, we acknowledge the important contribution of the International Development Research Centre and the World Health Organization/Special Programme for Research and Training in Tropical Diseases. 


\section{References}

1. Sotomayor H. Geopolítica y salud en la orinoquia Colombiana. Una mirada médica historico-social. Temas Méd 2003; XVI:56-8.

2. Gallagher EB. Sociological studies of third world health and health care: introduction. J Health Soc Behav 1989; 30:345-52.

3. Briceño-León R. La enfermedad de Chagas: una construcción social. In: Briceño-León R, Dias JCP, editores. Las enfermedades tropicales en la sociedad contemporánea. Caracas: Fondo Editorial Acta Científica Venezolana y Consorcio de Ediciones Capriles; 1993. p. 257-82.

4. Barreto ML, Teixeira MG. Dengue fever: a call for local, national, and international action. Lancet 2008; 372:205.

5. Guzman MG, Kouri G. Dengue and dengue hemorrhagic fever in the Americas: lessons and challenges. J Clin Virol 2003; 27:1-13.

6. Suárez MR, Olarte SM, Ana MF, González UC. Is what I have just a cold or is it dengue? Addressing the gap between the politics of dengue control and daily life in Villavicencio-Colombia. Soc Sci Med 2005; 61:495-502.

7. Parks WLL. Planificación de la movilización y comunicación social para la prevención y el control del dengue: guía paso a paso. Geneva: Organización Mundial de la Salud; 2004.

8. Hausmann-Muela S, Muela Ribera J, Nyamongo I. Health-seeking behaviour and the health system response. Bethesda: Disease Control Priorities Project; 2004. (Working Paper, 14).

9. Link BG, Phelan J. Social Conditions as fundamental causes of disease. J Health Soc Behav 1995; 35:80-94.

10. Link BG, Phelan JC. McKeown and the idea that social conditions are fundamental causes of disease. Am J Health Promot 2002; 92:730-2.

11. Maguiña Vargas C, Osores Plengue F, Suarez Ognio L, Soto Arquiguiño L, Pardo Ruiz K. Dengue clásico y hemorrágico: una enfermedad reemergente y emergente en el Perú. Rev Med Hered 2005; 16:120-40.

12. Oletta LJF. Dengue en América Latina y Venezuela. Med Interna 2006; 22:247-58.

13. Toledo-Romani ME, Vanlerberghe V, Perez D, Lefevre P, Ceballos E, Bandera D, et al. Achieving sustainability of community-based dengue control in Santiago de Cuba. Soc Sci Med 2007; 64:976-88.

14. Hunt LM, Mattingly C. Introduction: diverse rationalities and multiple realities in illness and healing. Med Anthropol Q 1998; 12:267-72.

15. Vezzani D, Carbajo AE. Aedes aegypti, Aedes albopictus, and dengue in Argentina: current knowledge and future directions. Mem Inst Oswaldo Cruz 2008; 103:66-74.

16. Sales FMS. Ações de educação em saúde para prevenção e controle da dengue: um estudo em Icaraí, Caucaia, Ceará. Cienc Saúde Coletiva 2008; 13: 175-84.

17. Heintze C, Garrido MV, Kroeger A. What do community-based dengue control programmes achieve? A systematic review of published evaluations. Trans R Soc Trop Med Hyg 2007; 101:317-25.
18. Mondini A, Chiaravalloti Neto F. Socioeconomic variables and dengue transmission. Rev Saúde Pública 2007; 41:923-30.

19. Ávila-Montes GA, Martínez M, Sherman C, Fernandez-Cerna E. Evaluación de un módulo escolar sobre dengue y Aedes aegypti dirigido a escolares en Honduras. Rev Panam Salud Pública 2004; 16:84-94.

20. Martinez-Vega RA, Díaz-Quijano FA, Villar-Centeno LA. Dificultad para el diagnóstico clínico del dengue en un área endémica y su impacto sobre el manejo médico inicial. Rev Med Chil 2006; 134:153-60.

21. Suárez R, Forero AM, Olarte MF. El dengue en Villavicencio: entre la realidad biológica y la realidad social. Bogotá: Uniandes; 2003.

22. Fajardo P, Monje CA, Lozano G, Realpe O, Hernández LE. Nociones populares sobre "dengue" y "rompehuesos", dos modelos de la enfermedad en Colombia. Rev Panam Salud Pública 2001; 10:161-8.

23. Coyne IT. Sampling in qualitative research. Purposeful and theoretical sampling; merging or clear boundaries? J Adv Nurs 1997; 26:623-30.

24. Quinn-Patton M. Qualitative methods \& evaluation methods. Thousand Oaks: Sage Publications; 2002.

25. Malterud K. Qualitative research: standards, challenges, and guidelines. Lancet 2001; 358:483.

26. Diallo D, Graz B, Falquet J, Traore AK, Giani S, Mounkoro PP, et al. Malaria treatment in remote areas of Mali: use of modern and traditional medicines, patient outcome. Trans R Soc Trop Med Hyg 2006; 100:515-20.

27. Chan Z. Essay: composing a song to teach about dengue fever. Lancet 2006; 368 Suppl 1:S22-3.

28. Phuanukoonnon S, Brough M, Bryan JH. Folk knowledge about dengue mosquitoes and contributions of health belief model in dengue control promotion in Northeast Thailand. Acta Trop 2006; 99:6-14.

29. Segall M, Dasen P, Berry L, Poortinga Y. Human behavior in a global perspective: an introduction to cross-cultural psychology. New York: Pergamon Press; 1990.

30. Lebel J. Health: an ecosystem approach. Ottawa: International Development Research Centre; 2003.

31. Glaser BG. Doing grounded theory: issues and discussions. Mill Valley: Sociology Press; 1998.

32. Strauss A, Corbin M. Basics of qualitative research: techniques and procedures for developing grounded theory. Thousand Oaks: Sage Publications; 1998.

33. Silverman D. Analyzing talk and text. In: Denzin NLY, editor. Handbook of qualitative research. London: Sage Publications; 2000. p. 821-34.

34. Porter D. Health, civilization and the state. London: Routledge; 1999.

35. Fals-Borda O. Autonomías en la nueva república. Bogotá: Tercer Mundo; 2000.

36. Rivas M. Los trabajadores de tierra caliente. Bogotá: Editorial Incunables; 1983. 
37. Heintze C, Garrido MV, Kroeger A. What do community-based dengue control programmes achieve? A systematic review of published evaluations. Trans R Soc Trop Med Hyg 2007; 101:317-25.

38. Toledo ME, Vanlerberghe V, Baly A, Ceballos E, Valdes L, Searret M, et al. Towards active community participation in dengue vector control: results from action research in Santiago de Cuba, Cuba. Trans R Soc Trop Med Hyg 2007; 101:56-63.

39. Kroeger A, Dehlinger U, Brukharehortua W, Anaya $\mathrm{H}$, Becker N. Community based dengue control in Colombia: people's knowledge and practice and the potential contribution of the biological larvicide Bti (Bacillus thuringiensis israelensis). Trop Med Parasitol 1995; (46):241-6.
40. Khun S, Manderson LH. Abate distribution and dengue control in rural Cambodia. Acta Trop 2007; 101:139-46.

41. Peretti-Watel P. Sociologie du risque. Paris: Armand Colin; 2000.

42. Peretti-Watel P. Du recours au paradigme épidémiologique pour l'étude des conduites à risque. Rev Fr Sociol 2004; 45:103-32.

43. Virchow R. Scientific methods and therapeutic standpoints. In: Rather L, editor. Disease, life and man. Standford: Standford University Press; 1958. p. 48-66.

Submitted on 20/Dec/2007

Final version resubmitted on 28/Aug/2008

Approved on 30/Sep/2008 